\section{Form and color as short-term memory codes in preschool children}

\author{
R. CONRAD* \\ Medical Research Council, Applied Psychology Unit, Cambridge, England
}

Using a matching procedure, children aged 3-4 years were given a serial recall task which tested short-term memory (STM) for objects. The test items were forms with color constant, different colors with form constant, or different forms each of different color. There was no recall difference when the available cue was either form or color alone. When both form and color were available, recall significantly improved. For children too young to mediate recall verbally, both form and color seem equally effective mediators, and are apparently used additively.

From about school age, there is a growing literature on the kind of short-term memory (STM) codes used by children (Flavell, 1970). For younger children, there is at present very little to go on. The nearest studies to this topic are probably those concerned with perceptual matching and especially visual matching of form and color. These do not involve STM, but are obviously relevant. They are also inconclusive. Corah (1966) reports that most studies show Ss of this age to be color dominant. Brian \& Goodenough (1929), however, report that children below 3 years are form dominant, and only above 5 years are color dominant. Trabasso, Stave, \& Eichberg (1969) also found Ss aged 4-5 to be form dominant.

There is a good deal of evidence that from about the age of 5 years children follow the adult pattern of STM coding: regardless of presentation mode, they recode the input to verbal form whenever it is available (Conrad, 1971; Flavell, 1970). Before this age, even though Ss demonstrably know the names of objects pictorially presented in a STM task, they do not use them to mediate recall. The implication seems clear that these $\mathrm{Ss}$ depend in a general sense on visual coding, since they do have a short-term memory. At about age 5 years, the predominant STM code changes, but at present we have little idea in detail of the code or codes used prior to that age. Colored pictures have at least three obvious dimensions which could be used as STM codes, namely, size, form, and color. The present study, holding size constant, considers the relative roles of form and

\footnotetext{
* For permission to test the children, the author is indebted to the Inner London Educational Authority and the Health Department of the London Borough of Tower Hamlets. Mrs. J. I. Phillips assisted throughout. Author's present address: Nuffield Hearing and Speech Centre, 330 Grays Inn Road, London, W.C.1, England.
}

color in STM when verbal coding has not developed.

METHOD

The test material consisted of colored plastic forms, each with an area very closely approximating to $25 \mathrm{sq} \mathrm{cm}$. Each form was mounted on sets were used: (1) color set (C)-five squares, one each of which was colored green, blue, yellow, orange, white; (2) form set $(F)-a$ square, a triangle, a circle, a rectangle, a cross, all of which were red; $(3)$ form-color set (FC)-a white square, a green triangle, a red circle, a yellow rectangle, a blue cross.

The procedure, which was the same for each set, was as follows. A set was displayed in front of $\mathbf{E}$ but within reach of $S$. One duplicate item of the set was placed before $S$ in the correct orientation. Using suitable language, $\mathbf{S}$ was instructed to move it to match the appropriate item in E's set. The S practiced with two- and three-item tasks until the matching task was clearly understood and correctly carried out. At this stage, no memory was required. Next, an item was presented to $S$, who inspected it. It was then turned over "face down," and $\mathbf{S}$ matched from memory. This was practiced for two and three items until $E$ was satisfied that the procedure was understood.

For each trial of the test proper, first $\mathrm{E}$ reordered the set of five items to which S's memorized items would be matched. This operation was concealed from $S$, and the set remained covered until all test items had been presented and turned over. This prevented matching by location. Then $E$ always presented three test items which were to be remembered. Each item was shown to $S$ for 1-2 sec and then turned over so as to form an upside-down array of three. At this point, E's set of five items was revealed, and $S$ attempted to match the test items from memory under a forced-guessing instruction. A more a square of thin board of $11 \mathrm{~cm}$. Three detailed description of this procedure, but using different test material, is given in Conrad (1971).

A complete test comprised 10 trials with each of the three different sets. The sets were used in strict rotation from trial to trial, but starting with each set with equal frequency. For all trials, all Ss attempted to match three items drawn from the total set of five. Selection of test items ensured that all were equally used.

The Ss were 24 children attending a day nursery and a nursery school. They were of chronological age 3-4 years and also of mental age 3-4 years measured by the English Picture Vocabulary Test, which is a British standardization of the Peabody. A test was spread over several sessions on different days. Two Ss failed to complete the test, and results are based on the remaining 22,11 of whom were boys.

\section{RESULTS}

The mean number (SD in parentheses) of items correctly matched per S (out of 30 ) was for the F, C, and FC sets, respectively: 10.6 (4.64), $11.4(4.35), 15.6$ (4.83). The difference between the $\mathrm{F}$ set and $\mathrm{C}$ set is not significant $(t<1)$. The FC set is significantly better than either of the others $(p<.001)$. There was no recall difference on any set between boys and girls.

At the end of the test, Ss were encouraged by suitable means to name each color and each form. The Ss had practically no success at all with the forms. When asked to identify the colors, all Ss were able to give some color names, but only $2 \mathrm{Ss}$ correctly named the set of six, 13 Ss named apparently haphazardly, and 7 Ss were correct on two or three colors.

\section{DISCUSSION}

On average, the Ss who knew all or some of the color names recalled no more of the $C$ set than the others. From other evidence (Conrad, 1971), it seems most unlikely that they were using names as verbal mediators-and, if they were, uncharacteristically it did not help.

The main result shows that at this age, given the opportunity, both form and color are dimensions of objects which may be used as STM codes with equal effectiveness within a group of Ss. But they do not seem to be used exclusively. When color is added to a form, or form added to a color, recall improves. To test whether this additivity of cues is a behavioral or simply an arithmetic effect, FC scores were compared with the better score, $\mathrm{F}$ or $\mathrm{C}$, for each $\mathrm{S}$. If the $\mathrm{FC}$ advantage was due to the fact that Ss were merely, and only, using their most effective single code, there would be no difference. In fact, a t test shows 
FC recall to be better than the best of $\mathrm{F}$ and $\mathrm{C}$ at $\mathrm{p}<.01$. Two cues here do seem to be better than one. This is different behavior from that of older children, who, when they use a verbal code in STM, appear to use it exclusively (Conrad, 1972).

Finally, we see little reason to expect either form or color to become more dominant for STM coding with children older or younger than those used here. By age 5, verbal coding begins to become the principal STM code when names are available to the child. With children aged less than 3 , we cannot of course be so certain. But there does not seem to be enough maturational time for a well-developed memory code to give place to another before the onset of verbal coding. Our provisional view is therefore that prior to the use of verbal coding in STM, if form and color are both equally available, they are equally effective-and apparently additive.

\section{REFERENCES}

BRIAN, C. R., \& GOODENOUGH, F. L The relative potency of color and form perception at various ages. Journal of Experimental Psychology, 1929, 12 197-213.

CONRAD, R. The chronology of the development of covert speech in children. Developmental Psychology, 1971, 5, $398-405$

CONRAD, R. Short-term memory in the deaf: A test for speech coding. British Journal of Psychology, 1972, in press.

CORAH, N. L. The influence of some stimulus characteristics on color and form perception in nursery-school children. Child Development. 1966, 37, 205-211.

FLAVELL, J. H. Developmental studies in mediated memory. In $\mathrm{H}$. W. Reese and $L$ P. Lipsitt (Eds.), Advances in child development and behavior. Vol. 5. New York: Academic Press, 1970.

TRABASSO, T., STAVE, M., \& EICHBERG, R. Attribute preference and discrimination shifts in young children. Journal of Experimental Child Psychology, 1969, 8, 195-209. 